\title{
Performance of Base Isolators and Tuned Mass Dampers in Vibration Control of a Multistoried Building
}

\author{
Julie $\mathrm{S}^{1}$, Sajeeb $\mathrm{R}^{2}$ \\ ${ }^{I} P$ G Student in Structural Engineering and Construction Management, Department of Civil Engineering, T K M \\ College of Engineering, Kollam, Kerala, India \\ ${ }^{2}$ Professor, Department of Civil Engineering, T K M College of Engineering, Kollam, Kerala, India
}

\begin{abstract}
Earthquakes create vibrations on the ground that are translated into dynamic loads which cause the ground and anything attached to it to vibrate in a complex manner and cause damage to buildings and other structures. Civil engineering is continuously improving ways to cope with this inherent phenomenon. Conventional strategies of strengthening the system consume more materials and energy. Moreover, higher masses lead to higher seismic forces. Alternative strategies such as passive control systems are found to be effective in reducing the seismic and other dynamic effects on civil engineering structures. The present paper focuses on the performance evaluation of a few passive control systems such as base isolation systems and tuned mass dampers in the vibration control of a linear multi storied structure under harmonic and earthquake base motions. Base isolators such as Lead Rubber Bearing (LRB) system and Friction Pendulum System (FPS); and, a tuned mass damper (TMD) are designed for a ten storied reinforced concrete building. The building is modelled as a 10 degrees of freedom shear building model and Bouc Wen model is used to describe the hysteretic behaviour of base isolators. The performance of LRB system, FPS and TMD are evaluated numerically and compared. The frequency response characteristics of the systems are also studied.
\end{abstract}

Keywords - Base isolation, Hysteresis, Lead rubber bearing, Friction Pendulum, Passive control, Tuned mass damper.

\section{INTRODUCTION}

Earthquakes are occasional forces on structures that may occur during the lifetime of buildings. As seismic waves move through the ground, they create a series of vibrations. These movements are translated into dynamic loads or inertial forces that cause the ground and anything attached to it to vibrate in a complex manner. These inertial forces cause damage to buildings and other structures. In regions where seismicity is insignificant, the conventional design approach aims at the design of structural members in such a way that static (gravitational) and dynamic loads (such as wind load) are withstood elastically. However, if this design approach was to be followed in cases where seismic excitation had to be taken into account, this might lead to energy inefficient and economically unacceptable design solutions. Moreover, this strategy leads to higher masses and hence higher seismic forces. Therefore, alternative design concepts are often chosen. [1]. Passive control strategies focus on reducing the effect of earthquake instead of increasing the strength of members. The developments in passive control of structures and their applications to earthquake resisting design are reviewed in article [2]. Seismic isolation systems and passive energy dissipation systems like viscoelastic dampers, hydraulic devices or lead extrusion systems; or the addition of hysteretic damping through the use of frictionslip devices, metallic yielding devices, or shape-memory alloy devices are examples of passive control systems. [3].Seismic isolation is a concept in earthquake engineering introduced in the early 1980s in the USA and New Zealand, and as early as 1975 in the former Soviet Union [4]. The idea underlying the technology is to detach the building from the ground in such a way that the earthquake motions are not transmitted up through the building, or are at least greatly reduced [1]. Details of base isolation systems are available in works of [5] and [6].

Base isolators lengthen the fundamental period of the structure to be controlled. There are two common types of seismic isolation systems: Elastomeric bearings (e.g. lead-rubber bearings) and sliding bearings (e.g. Friction pendulum systems). The elastomeric isolators use the low lateral stiffness of the material to increase the fundamental period whereas the sliding systems use the characteristics of a pendulum to lengthen the period. Another passive control which is widely used is tuned mass damper (TMD). TMD system can be installed to new or existing structures to improve their resistance to earthquakes and winds. A TMD system consists of a mass, a spring and a damper. If these properties are properly designed and selected, then the TMD device can be effective in suppressing undesirable vibrations induced by earthquake or wind loads [7]. Design of a TMD for a given structure implies estimating the parameters of the TMD to effectively control the vibration of the given structure. Systematic procedures have been developed for the design of TMDs. [8] and [9]. 
The present paper focuses on the performance evaluation of base isolation systems and tuned mass dampers. The objective is to study the effectiveness of these passive control techniques on vibration control of linear multi storied buildings under harmonic and earthquake ground excitation, using numerical analysis. Base isolators like lead rubber bearing and friction pendulum system; and, TMD are designed for a multistoried building and their performances are evaluated and compared.

\section{DESCRIPTION OF THE STRUCTURE}

The structure to be controlled is a symmetric 10 storied building. The plan of the structural system of the building is shown in Fig. 1. Structural specifications are as follows: Room height $=3000 \mathrm{~mm}$, Wall thickness $=230 \mathrm{~mm}$, Slab thickness $=120 \mathrm{~mm}$, Column size $=230 \mathrm{~mm} \times 600 \mathrm{~mm}$, Beams $=230 \mathrm{~mm} \times 400 \mathrm{~mm}$. The structure may be modelled as 10 degree of freedom shear building model. The entire mass of the building is assumed to be lumped at the floor. The stiffness is contributed by columns in each storey.

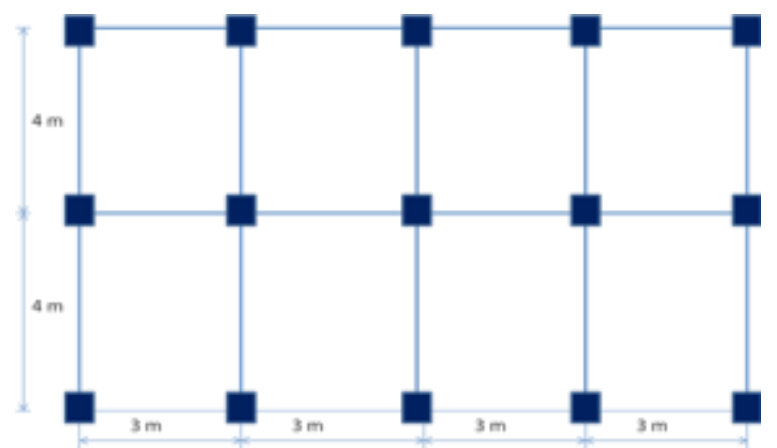

Fig. 1 Plan of the 10 Storied Building

The spring-mass model of the structure is shown in Fig. 2. The floor masses (starting from bottom) are worked out to be $m_{1}=m_{2}=\ldots . m_{9}=157900 \mathrm{~kg}$ and $m_{10}=98500 \mathrm{~kg}$. The storey stiffness values are found to be $k_{1}=k_{2}=\ldots . . k_{10}=7.5586^{\times} \times 10^{8} \mathrm{~N} / \mathrm{m}$ (assuming M30 concrete). From the free vibration analysis, the fundamental frequency of the structure is found out as $10.72 \mathrm{rad} / \mathrm{s}$ resulting in a time period of $0.5859 \mathrm{~s}$. The damping is assumed to be proportional to stiffness, the proportionality constant being 0.00187 . i.e., $c_{i}=0.00187 k_{i}(i=1,2,3$, . $., 10)$.

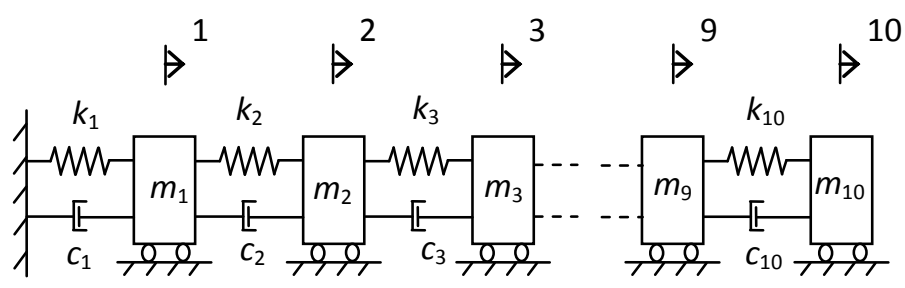

Fig. 2 Spring-Mass Model of the Building

\section{DESIGN OF BASE ISOLATORS AND TMD}

The entire superstructure is supported on discrete isolators. In the present paper two types of isolators are considered - friction pendulum system (FPS) and lead rubber bearing (LRB) isolator. The design of isolators is carried out as per the guidelines of International Building Code 2000 (IBC-2000). The design parameter of friction pendulum system is the radius of curvature of the pendulum and horizontal stiffness of the isolator. Here, assuming a target period of $2 \mathrm{~s}$, the radius of curvature is obtained as $1 \mathrm{~m}$. The effective stiffness of the FPS isolation system, $K_{f}$ is worked out to be $18.24 \times 10^{6} \mathrm{~N} / \mathrm{m}$. For the design of LRB isolators, a rubber compound with a shear modulus, $\mathrm{G}=0.414 \mathrm{~N} / \mathrm{mm}^{2}$ is assumed. The target period of 2.5 seconds is assumed. The required stiffness corresponding to this period is found to be $K_{R H}=9.78 \times 10^{6} \mathrm{~N} / \mathrm{m}$. Each isolator has a lead plug, with an isolator diameter of $800 \mathrm{~mm}$ and lead plug diameter of $70 \mathrm{~mm}$ and having a total thickness of $530 \mathrm{~mm}$.

The most significant design variable for TMD is the mass ratio ( $\left.\mu_{s \mathrm{~m}}\right)$. When the mass ratio increases, the TMD becomes more effective and robust. In most applications the mass ratio is designed to be in the range of $1-10 \%$.In the present study, for the design of TMD, a mass ratio of 0.1 is adopted. The mass of the TMD is worked out to be $151960 \mathrm{~kg}$. It may be noted here that the roof area $(12 \mathrm{~m} \times 8 \mathrm{~m})$ is sufficient to accommodate the mass of the TMD. The optimum natural frequency of the damper $(f a)=9.75 \mathrm{rad} / \mathrm{s}$. The stiffness of the TMD spring is worked out to be $1.44 \times 10^{7} \mathrm{~N} / \mathrm{m}$ and the optimum damping ratio of damper ( $\left.\xi_{\mathrm{op} t}\right)$ is found as 0.1679 . 


\section{PERFORMANCE OF BASE ISOLATORS}

Accurate modelling of the base-isolated structure is required, to be able to analyse and predict its seismic performance. Most isolation systems exhibit a (highly) nonlinear behaviour [10].To describe the behaviour of hysteretic processes several mathematical models have been proposed. In many cases, next to constitutive models, the Bouc-Wen model is widely used [11].It was introduced by Bouc and extended by Wen, who demonstrated its versatility by producing a variety of hysteretic characteristics. The Bouc-Wen model can match a hysteretic behaviour by properly tuning its parameters. It is a black-box model, i.e. the model parameters may not have physical meaning [10]. Moreover, the model is in the form of a differential equation and is thus easy to incorporate in the equations of motion of the superstructure. A brief description of the BoucWen model is provided here.

For forced single degree of freedom hysteretic oscillator, the equation of motion using the Bouc-Wen model is given as

$$
m x+c x+a k x+(1-a) k z=f
$$

where $m, c, k, f, a$ are the mass, damping coefficient, stiffness, external excitation ,plastic to elastic stiffness ratio respectively. The hysteretic auxiliary variable $\mathrm{z}$, as per Bouc-Wen model is given as $z=A x^{x}-\|z\|^{12}(y \operatorname{sign}(x z)+\beta) x^{x}$

where ${ }^{A_{v} \beta_{v} \gamma}$ are parameters that control the hysteretic loop shape and ${ }^{n}$ affects the smoothness of the hysteretic curve. The parameters $A_{2} \beta_{s y}$ and ${ }^{n}$ play the role of governing and controlling the scale and general shape of the hysteresis loop. In the present study, the hysteretic behaviour of both the isolators are described by Bouc-Wen model with appropriately chosen parameters.

The structure when considered with base isolator will be an 11 dof system with base mass, ${ }^{m_{b}}$. The base mass is taken as equal to mass of each storey, i.e. $m_{b}=15.79 \times 10^{4} \mathrm{~kg}$. The first dof corresponds to the movement of base mass $\left.{ }^{m_{b}}\right)$ and the $11^{\text {th }}$ dof corresponds to the movement of the top floor $\left(10^{\text {th }}\right.$ floor of the given structure). The response of the structural system - 10 dof shear building model supported on isolators - is found out using codes developed in Matlab. Time history analysis is performed using $4^{\text {th }}$ order Runge Kutta Method with a time step chosen of $0.02 \mathrm{~s}$. In all cases the structure is assumed to start from rest. It may be noted here that the restoring force (in the isolator) is given by the equation, $f_{z}=k_{b} x_{1}+(1-a) k_{b} z$ where $x_{1}$ is the displacement of the base mass. The hysteretic auxiliary variable, ${ }^{z}$ of the Bouc-Wen model is given by $z=A x_{1}^{n}-\|z\|^{n}\left(y \operatorname{sign}\left(x_{1}^{n} z\right)+\beta\right) x_{1}^{n}$.

For the designed FPS isolator, the following parameters are assumed for the Bouc-Wen model: $a=0.1, A=4, \beta=0.50, \gamma=0.50, n=2$. The Bouc-Wen parameters of the LRB isolator are chosen as: $a=0.1_{s} A=12, \beta=0.2, y=0.2, n=1$. The base motion considered in the present study is the ground acceleration of the El Centro earthquake.

Neglecting the nonlinear terms in the restoring force of the isolators, a free vibration analysis of the base isolated structure is performed and the fundamental period is found to be $1.9387 \mathrm{~s}$. An increase in the fundamental period is noted compared to that of the fixed structure $(0.5859 \mathrm{~s})$. The response of the given structure with FPS isolators are evaluated and compared with the response of the fixed base structure. The results are shown in Figs 3 and 4.

In Fig. 3(a) bottom of base isolator is shown by ordinate ' -1 ' (y axis) and ground level is shown by ordinate ' 0 '.From the analysis it can be noted that, when FPS is used maximum displacements and interstorey drifts of all floors are substantially reduced.

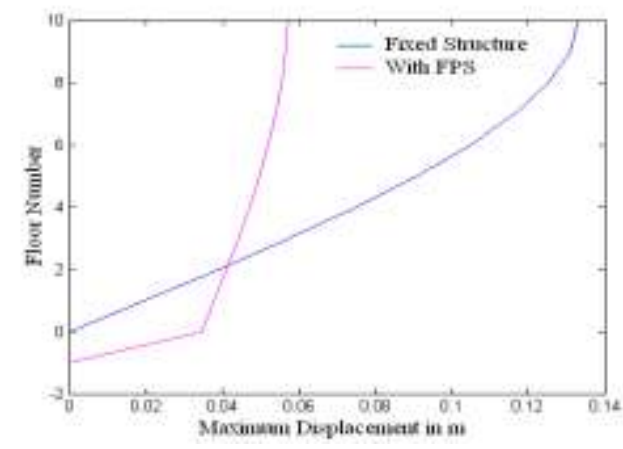

(a) 


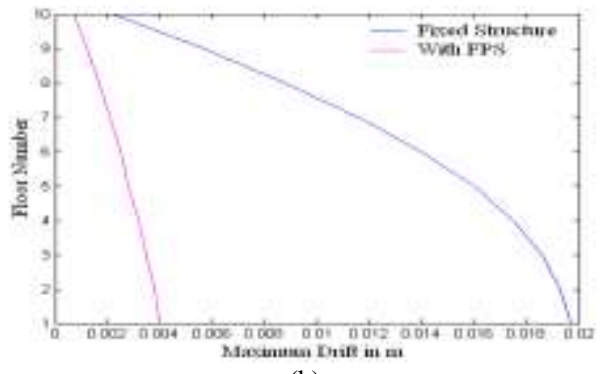

(b)

Fig. 3. Performance of FPS system (a) Maximum displacement (b) Interstorey drifts

It may be observed that the upper storeys of the base isolated structure moves almost like a rigid block. As a consequence of this the interstorey drifts are considerably reduced. Inter- storey drift is more at the lower floors and found to reduce towards the upper storeys. The interstorey drifts of the topmost storey of the base isolated structure is found to be lesser compared to that of fixed base structure.

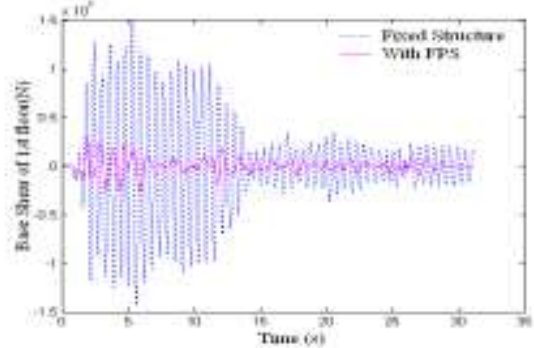

(a)

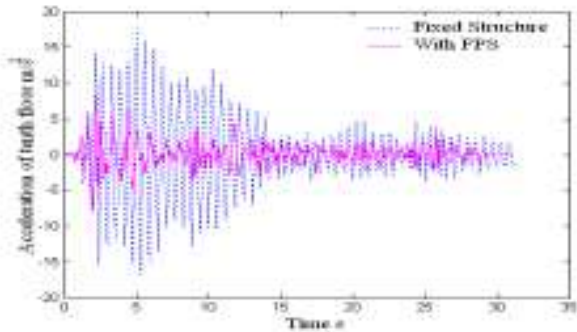

(b)

Fig. 4 Performance of FPS system - Time histories of responses (a) Base shear (b) Acceleration of tenth floor

A substantial reduction in shear force and acceleration is observable for all floors when isolators are used. The reduction in the shear force is attributed to the reduced interstorey drifts. Similar results are observed in case of LRB isolator also.

\section{PERFORMANCE OF TUNED MASS DAMPER}

A free vibration analysis of the given structure with the designed TMD placed at its top is performed. The fundamental time period is found to increase from $0.5859 \mathrm{~s}$ to $0.7663 \mathrm{~s}$. Unlike the case of base isolator, the increase in the fundamental period of the structure is only marginal, due to the installation of TMD. To compare the frequency response of the uncontrolled structure and structure with TMD, harmonic external excitation frequencies ranging from $1 \mathrm{rad} / \mathrm{s}$ to $30 \mathrm{rad} / \mathrm{s}$ is considered. Amplitude of base motion is selected in such a way that, amplitude of acceleration is $10 \mathrm{~m} / \mathrm{s}^{2}$, for all excitation frequencies. The frequency response of the maximum displacement and acceleration of $10^{\text {th }}$ floor is plotted and shown respectively in Fig. 5 and Fig. 6.

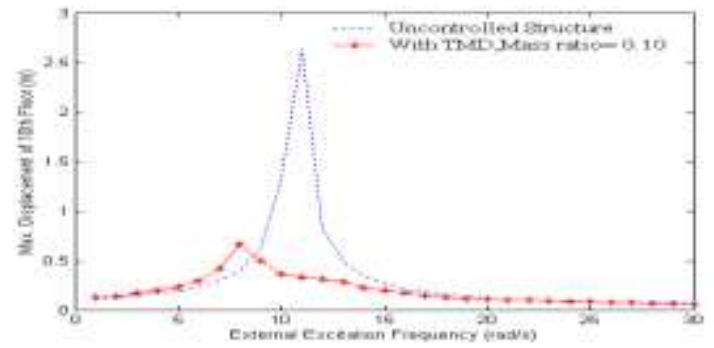

Fig.5 Frequency response of maximum displacement of top floor 


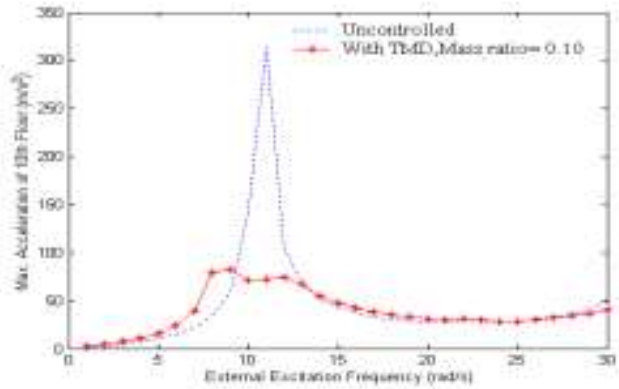

Fig.6 Frequency response of maximum acceleration of top floor

TMD is found to be effective in reducing the displacement response for frequencies in the neighbourhood of the fundamental frequency only and no control in displacement response can be observed for larger frequencies (Fig.5). Moreover, TMD is found to be effective in reducing acceleration response only for a narrow frequency range nearer to the fundamental frequency of the system (Fig.6). For lower frequencies TMD is not found to be effective in controlling both displacement and acceleration.

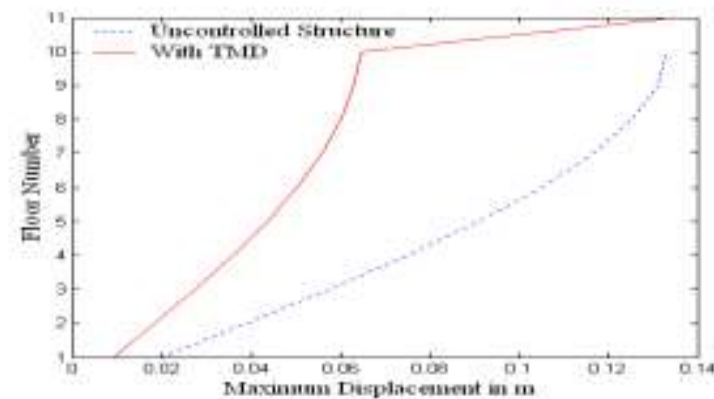

(a)

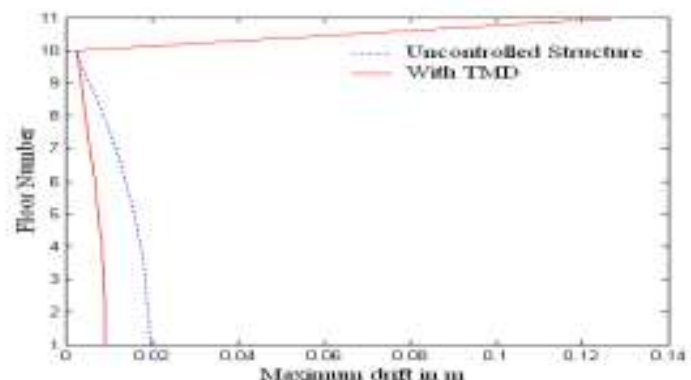

(b)

Fig. 7 Performance of TMD (a) Maximum displacement (b) Interstorey drifts

Note that floor number '11' corresponds to TMD in Fig 7(a) and (b). From Fig 7(a) it can be noted that maximum displacement is for the TMD and also when TMD is used, the maximum displacements of all floors are substantially reduced. From Fig. 7(b), it is evident that the TMD experiences maximum drift whereas the super structure experiences very less drift. However, unlike base isolated structures, the reduction in the inter storey drift of the upper storeys are lesser.

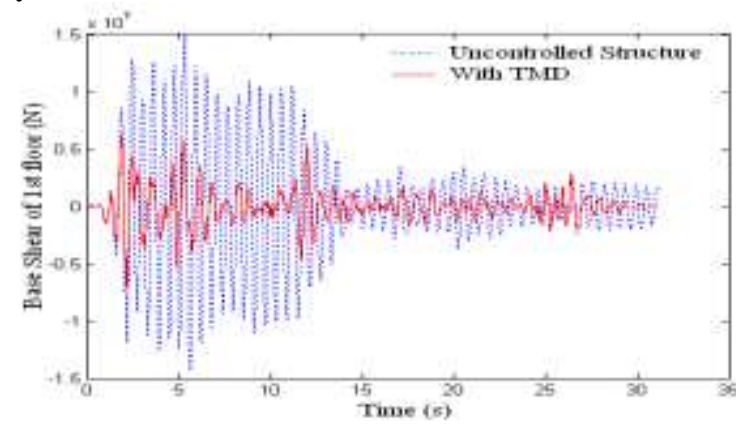

(a) 


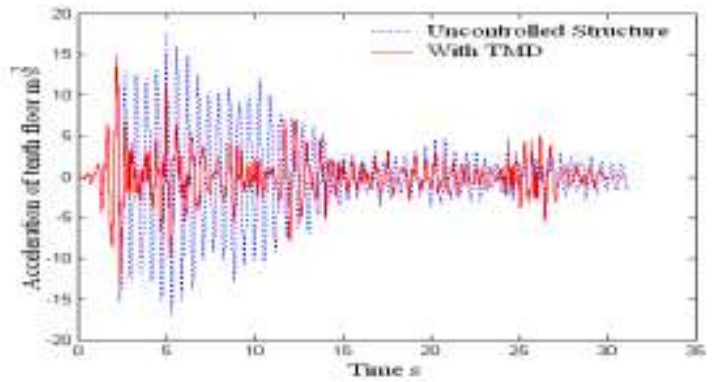

(b)

Fig. 8 Performance of TMD- Time histories of responses (a) Base shear (b) Acceleration of tenth floor

For the structure with TMD a substantial reduction in shear force is observable for first floor (Fig.8 (a)). But it is noted that an increase in value is seen specifically in top floor. Also, the acceleration experienced in the first floor of structure with TMD is lesser when compared with that of uncontrolled structure. From Fig 8 (b) it may be observed that the maximum acceleration experienced by top floor of the TMD installed structure never exceeds that of the uncontrolled structure.

\section{COMPARISON OF PERFORMANCE OF BASE ISOLATORS AND TMD}

To compare the performance of the designed base isolators (FPS and LRB) and TMD on the given structure, the frequency response of maximum displacement and maximum acceleration of the $10^{\text {th }}$ floor of the given structure are computed for harmonic base motions of frequencies ranging from $1 \mathrm{rad} / \mathrm{s}$ to $30 \mathrm{rad} / \mathrm{s}$. Amplitude of base motion is selected such that, amplitude of acceleration is $10 \mathrm{~m} / \mathrm{s}^{2}$, for all excitation frequencies. To plot the curves, the maximum values of responses at steady state are noted. The frequency response curves are shown in Fig. 9 and Fig. 10.

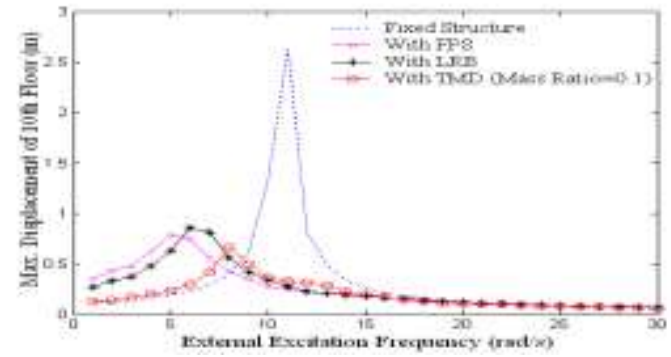

Fig. 9 Performance of Base isolators and TMD in displacement control

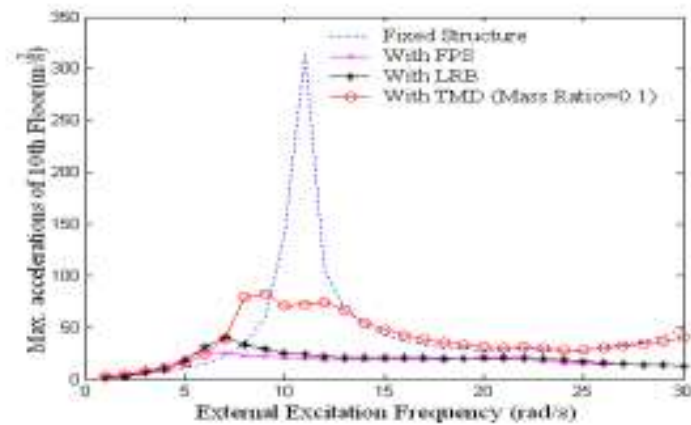

Fig. 10 Performance of Base isolators and TMD in acceleration control

It may be observed from Fig 9 and 10 that, for very low frequencies of external excitation, which is uncommon or not dangerous, both TMD and base isolator are not found to be effective in controlling the displacement response and acceleration response. Compared to structure with TMD, base isolated structures perform poorly in the low frequency regions. But when the frequency of external excitation is nearer to the fundamental frequency of the structure, both base isolators and TMD are found to be effective in reducing displacement and accelerations. In this frequency range, base isolators are found to perform well compared to TMD. In controlling acceleration in the resonant frequency range, base isolators are superior to TMD. In the high frequency range both TMD and base isolators are not found to offer any control, with respect to controlling maximum displacement. However, base isolators are found to be better than TMD in the high frequency range in controlling acceleration. One may clearly observe that the use of base isolator and TMD avoids resonance condition there by eliminates the chance of collapse of the structure. 


\section{CONCLUSION}

The present study deals with investigating the effects of a few passive control systems on the response of a multi storied building. Base isolation systems such as friction pendulum system and lead rubber bearing are designed and their effect on the response control of the given multi degree freedom system is investigated. A tuned mass damper is also designed for the given structure. Its effect on the response control of the structure is investigated. The performance of base isolators and TMD are compared with reference to their effectiveness in controlling the displacement and acceleration. The excitation considered is the base acceleration of the El Centro earthquake. It must be emphasized here that, for a new building to be constructed, base isolators are to be designed in the preliminary stage of the design itself and should be installed before the construction of the super structure. In case of TMD, it can be designed and installed even after the construction of the building. Base isolators and TMD are found to be effective in the neighbourhood of the fundamental resonant frequency of the structure. Base isolators are found to be superior in controlling the acceleration response. However, for base motions of low frequencies base isolators perform badly.

Several practical systems of seismic isolation have been developed and implemented in recent years, and interest in the application of this technique continues to grow. Although seismic isolation offers significant benefits, it is by no means a panacea. Feasibility studies are required early in the design phase of a project to evaluate both the technical and the economic issues. If its inclusion is appropriate from a technical and first-cost perspective, then significant life-cycle cost advantages can be achieved. Thus, seismic isolation represents an important step forward in the continuity search for improved seismic safety.

\section{REFERENCES}

[1] SaifulIslam, A.B.M, Jameel, M and Jumaat, M.Z, Seismic isolation in buildings to be a practical reality: Behavior of structure and installation technique, Journal of Engineering and Technology Research, Vol. 3(4), 2011, 99-117

[2] Ahmadi, G ,Overview of base isolation, passive and active vibration control strategies for aseismic design of structutres, Scientia Iranica, Vol.2,No.2,1995,99-116

[3] Soong,T.T and Constantinou, M.C,Passive and active structural vibration control in civil engineering, International center for mechanical sciences, Courses and lecturers No.345,1994

[4] Mayes, R.L, Naeim, F ,Design of Structures with Seismic Isolation,, International Thomson publishing Asia,Singapore, 2001,723756

[5] Naderzadeh, A, Application of seismic base isolation technology in Iran, Menshin No.63 Imensazeh Company, Tehran, 2009, 4047

[6] Wang and Yen-Po, Fundamentals of seismic base isolation, International training programs for seismic design of building structutres, 2009,139-148

[7] Abdulsalam, I, Al-Janabi, M , and Al-Taweel, M.G, Optimum design of tuned mass damper systems for seismic structures, Earthquake Resistant Engineering Structures VII, WIT Transactions on The Built Environment, Vol 104,2009,175-184

[8] Saidi, I, Mohammed, A. D, Gad, E F, Wilson, J.,L and Haritos, N, Optimum design for passive tuned mass dampers using viscoelastic materials, Australian Earthquake Engineering Society Conference ,2007,1-8

[9] Sadek, F, Mohraz, B, Taylor, A.W and Chung, R .M ,A method of estimating the parameters of tuned mass damper for seismic applications, Earthquake engineering and structural dynamics, Vol 26,1997,617-63

[10] Ismail, M , Ikhouane, F and Rodellar, J, The Hysteresis Bouc-Wen Model, a Survey, Arch Comput Methods Eng 16,2009, 161188

[11] Suy, H.M.R, Nonlinear dynamic analysis of a structure with a friction-based seismic base isolation system , master thesis report, Eindhoven University of Technology, Netherlands,2005. 